\title{
Efficiency of uronic acid uptake in marine alginate- degrading fungi
}

\author{
K. Schaumann \& G. Weide \\ Alfred-Wegener-Institute for Polar-and Marine Research; Am Handelshafen 12, \\ D-27570 Bremerhaven, Germany
}

\begin{abstract}
Despite the fact that many marine fungi, including phycomycetes, yeasts, ascomycetes and hyphomycetes, have been recorded from living and/or dead phaeophytes, only a few of these have been shown to be capable of degrading alginic acid or alginates. The degradation is achieved by the action of an exoenzyme complex, comprising alginate lyase, as well as alginate hydrolase activities. The latter was detected only recently by the authors. In this study, the growth of two marine sodiumalginate-degrading deuteromycetes, Asteromyces cruciatus and Dendryphiella salina, was investigated, and the assimilation efficiency of sodiumalginate and its uronic acid degradation products, respectively, was estimated from the economic coefficient $(E)$. $E$ is calculated from the mycelial dry weight, divided by the weight of substrate consumed for this production. The economic coefficient for A. cruciatus was $48.6 \%$, and that of D. salina $38.9 \%$. This indicates that the former species uses the alginate degradation products more efficiently than the latter. The observed E-values for the marine deuteromycetes agree with those from other fungi, e.g. terrestrial species. In general, it is concluded that the marine fungi appear to play a more important role in kelp-based ecosystems than was realized previously.
\end{abstract}

\section{INTRODUCTION}

Alginates are both biologically and technologically important natural polysaccharides. They are produced predominantly by the marine brown algae (Phaeophyta), but also by some bacteria, e.g. Azotobacter vinelandii and Pseudomonas aeruginosa (Bushell, 1983; Schlegel, 1985). Between 15 and $40 \%$ of brown algal dry weight may consist of alginates (Lüning, 1985). Year after year, vast amounts of this dominant component of brown algal cell walls and intercellular mucilage are produced in the sea by algal photosynthesis. Most of this production, in the form of living or dead material, dissolved and particulate substances, constitutes the nutritional basis of a diverse array of organisms, e.g. herbivorous predators, detrivorous animals, suspension feeders, phagotrophic protozoa, and osmotrophic degraders like the bacteria and fungi (cf. Lüning, 1985; Rieper-Kirchner, 1989).

The role of marine fungi in the decomposition and reabsorption processes of marine algal materials is not well documented. Marine fungi, including phycomycetes, yeasts, ascomycetes and hyphomycetes, have been recorded in high numbers living in or on phaeophytes (Chan \& McManus, 1969; Gunkel et al., 1983; Haythorn et al, 1980; Kohlmeyer \& Kohlmeyer, 1979; Miller \& Whitney, 1981; Schatz, 1980, 1984). Only a few 
of these have been shown capable of degrading alginic acid or alginates (Chesters \& Bull, 1963; Wainwright, 1980; Wainwright \& Sherbrock-Cox, 1981). Therefore, some authors have suggested that the marine fungi might be of little, or even no significance, in the decomposition of alginates or brown algal material in the natural environment (Chesters et al., 1956; Chesters \& Bull, 1963; Waksman et al., 1934).

However, Schaumann \& Weide (1990) were able to show that 12 out of 72 strains of higher fungi isolated from marine habitats were capable of active alginate degradation. These belonged to only three different species: the deuteromycetes Asteromyces cruciatus Moreau \& Moreau ex Hennebert and Dendryphiella salina (Suth.) Pugh \& Nicot, and the ascomycete Corollospora intermedia Schmidt. One other species, Dendryphiella arenaria Nicot, has been shown capable of alginate degradation (Wainwright \& Sherbrock-Cox, 1981). For the deuteromycetes, an alginase enzyme complex comprising alginate lyase as well as alginate hydrolase - has been identified, and also the alginate degradation products characterized in detail by Schaumann \& Weide (1990).

In the present paper, we report on the growth and biomass production of one strain each of A. cruciatus and D. salina, relative to the consumption of sodiumalginate and its degradation products, i.e. of the various saturated and unsaturated monomers, di- and oligomers of D-mannuronic and L-guluronic acids. The efficiency of the alginate substrate utilization is calculated, and the ecological relevance of the findings is discussed.

\section{MATERIALS AND METHODS}

The materials and methods used were described previously in Schaumann \& Weide (1990). The fungi selected for this study were Asteromyces cruciatus, strain KMPB H 54 a, and Dendryphiella salina, strain KMPB H 800/1. KMPB = "Kulturensammlung Mariner Pilze, Bremerhaven" (Culture Collection of Marine Fungi, Bremerhaven). The composition of the sodiumalginate nutrient broth (NaPYNS) was: sodiumalginate extracted from marine brown algae (Protanal SF-DL) $10.0 \mathrm{~g}$; peptone (from casein) $0.5 \mathrm{~g}$; yeast extract $0.1 \mathrm{~g}$; ammoniumnitrate $1.0 \mathrm{~g}$; artificial seawater free of calcium and strontium ions (prepared according to Lyman \& Fleming, 1940) $1 \mathrm{~L} ; \mathrm{pH} \mathrm{7.4.} \mathrm{The} \mathrm{fungi} \mathrm{were} \mathrm{grown} \mathrm{in}$ semi-submerged static culture at $25^{\circ} \mathrm{C}$ in the dark. $100 \mathrm{ml}$ Erlenmeyer flasks were filled with $25 \mathrm{ml}$ nutrient broth and inoculated with a single agar-culture-disc of $3 \mathrm{~mm}$ diameter. Biomass production, determined as mycelial dry weight, and the successive liberation of degradation products from sodiumalginate were each measured in triplicates after $3,5,8,11$, and 25 days of culture. Consumption of uronic acids was measured by the meta-hydroxydiphenyl method of Blumenkrantz \& Asboe-Hansen (1973) at the end of the experiment. The assimilation efficiency of sodiumalginate and its uronic acid degradation products was estimated according to Perlman (1965) by the economic coefficient (E), which is calculated from the mycelial dry weight, divided by the weight of substrate consumed for this production.

\section{RESULTS}

\section{Fungal growth in sodiumalginate broth}

Following inoculation, the fungal mycelia developed rapidly and formed increasingly dense mats, particularly at the surface. The surface was completely covered by 


\section{Mycelial Production}

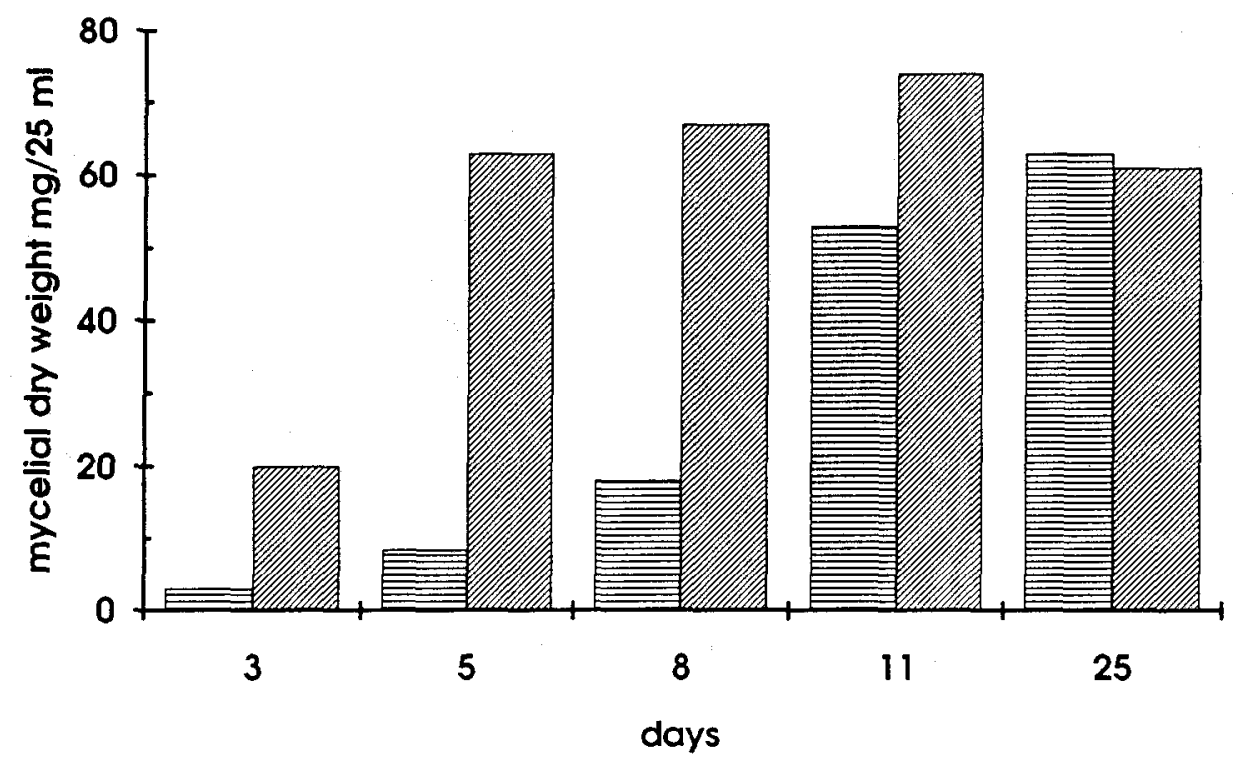

\section{Asteromyces cruciatus Dendryphiella salina}

Fig. 1. Mycelial dry-weight production of two marine deuteromycete fungi grown in sodiumalginate nutrient broth (NaPYNS) at $25^{\circ} \mathrm{C}$ in the dark

Dendryphiella salina on day 5 , and by Asteromyces cruciatus only on day 11. Production of conidia at the surface started in $D$. salina on day 8 and in $A$. cruciatus on day 11 . At the end of the experiment, day 25 , both cultures were covered by olive-green sporemasses on the surface. The results of successive dry-weight determinations are illustrated in Figure 1. D. salina grew rapidly during the first 5 days, then slowed down and finally declined, most probably due to autolysis. In contrast, $A$. cruciatus showed a more moderate growth at the beginning, then between day 8 and 11 increased dramatically, and afterwards exhibited a slow decrease. Although the growth of A. cruciatus lagged behind $D$. salina by about 5 days, both fungi reached nearly identical mycelial dry-weight productions at the end of the experiment.

Growth of the same strains on glucose, substituting sodiumalginate, was only slightly better (data not shown). This means that, under the given conditions, the two marine fungi can utilize sodiumalginate and its degradation products nearly as efficiently as glucose, the normally preferred carbon substrate.

The sodiumalginate substrate was degraded by the action of enzymes produced by the fungal mycelia. This is documented by the occurrence of alginate-degradation products in the fungal cultures (Figs 2,3 ). Both the reducing substances and unsaturated uronic acids, together with deoxy-keto-uronic acids, increased during the first days of 


\section{Asteromyces cruciatus}

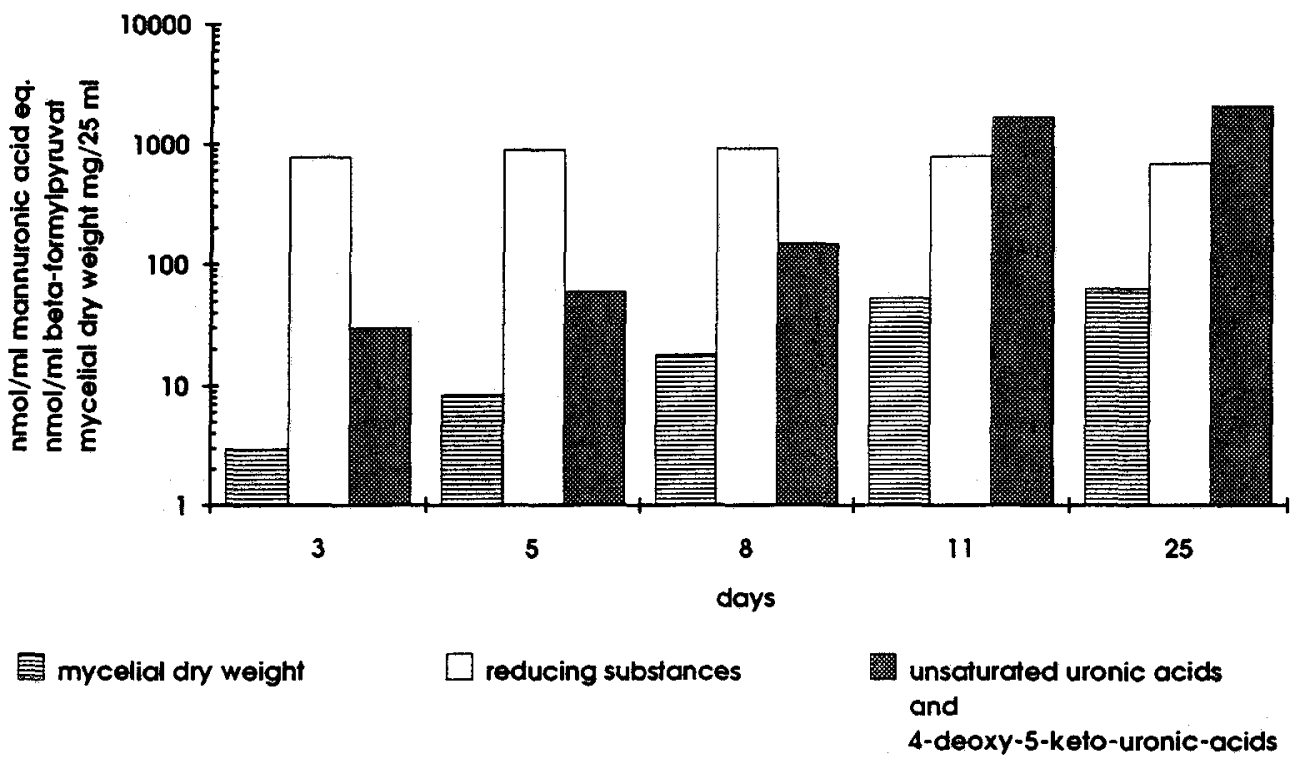

Fig. 2. Growth (mycelial dry weight), and concentrations of reducing substances (measured as mannuronic acid equivalents) and of unsaturated and 4-deoxy-5-keto-uronic acids (measured as $\beta$ formyl-pyruvate) produced by Asteromyces cruciatus in sodiumalginate nutrient broth (NaPYNS) at $25^{\circ} \mathrm{C}$ in the dark

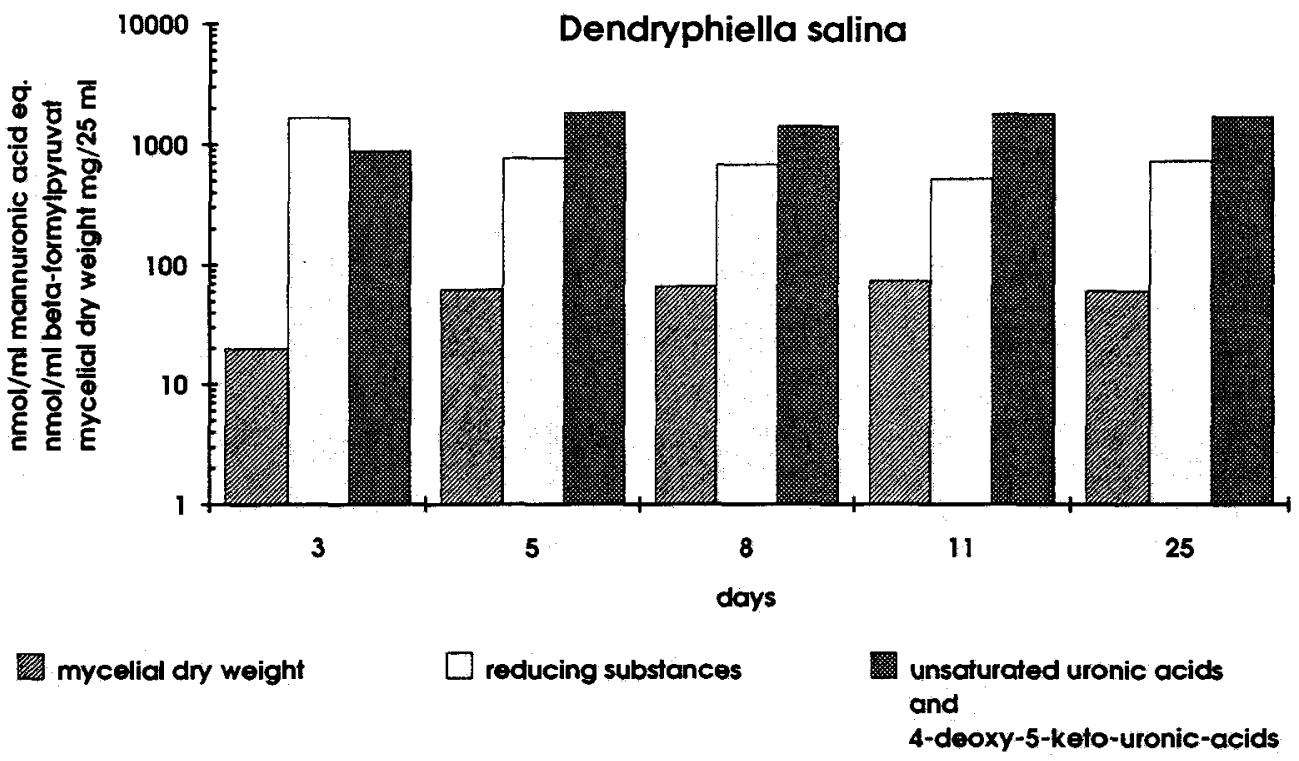

Fig. 3. Growth (mycelial dry weight), and concentrations of reducing substances (measured as mannuronic acid equivalents) and of unsaturated and 4-deoxy-5-keto-uronic acids (measured as $\beta$ formyl-pyruvate) produced by Dendryphiella salina in sodiumalginate nutrient broth (NaPYNS) at $25^{\circ} \mathrm{C}$ in the dark 
culture, but from day 8 in $A$. cruciatus and from day 3 in $D$. salina, an opposite pattern was exhibited: while the uronic acids were still increasing, the reducing substances were decreasing, obviously due to preferential fungal consumption. Therefore, we measured the production of alginate-degradation products in cell-free reaction mixtures, using culture filtrates from $D$. salina and fresh alginate substrate (Fig. 4). It demonstrates that, within 25 hours, both of the degradation products increase - the reducing substances four-fold and the uronic acids only two-fold (relative to the starting concentrations). In comparison with Figures 2 and 3, this indicates that two to four times more reducing substances than unsaturated and deoxy-keto-uronic acids are absorbed by the fungi.

\section{Dendryphiella salina}

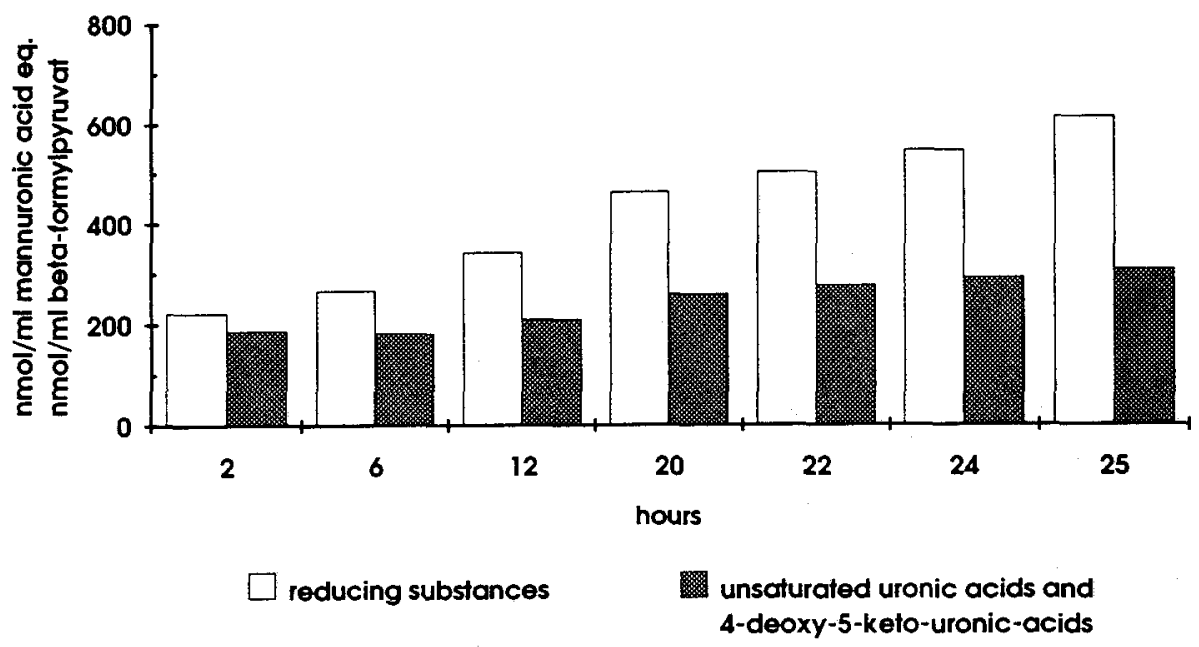

Fig. 4. Release of reducing substances (measured as mannuronic acid equivalents) and of unsaturated and 4-deoxy-5-keto-uronic acids (measured as $\beta$-formyl-pyruvate) produced by cell free Dendryphiella salina culture filtrates incubated with fresh sodiumalginate solution at $\mathrm{pH} 7.8$ and $25^{\circ} \mathrm{C}$

The characteristic physico-chemical structure of the sodiumalginate macromolecule and the pattern of its enzymatic degradation by the marine deuteromycetes, together with the reducing and non-reducing, poly-, oligo- and monomeric, saturated and unsaturated uronic acid degradation products have been described already in our preceding paper (Schaumann \& Weide, 1990).

\section{Uptake, metabolism and substrate utilization efficiency}

Having shown effective sodiumalginate degradation and concomitant growth of the fungi, two important questions arise: To what extent are the degradation products taken up, and how efficiently are they assimilated and converted into fungal biomass?

That the alginate-regradation products are indeed taken up by the fungi and used as 
energy and carbon source is evident from the fact that, parallel to mycelial dry-weight production, the concentrations of reducing substances and uronic acids decreased in comparison to the cell-free controls. Moreover, the fungi exhibited growth and dryweight production in amounts which far exceeded the weight of nutrients other than sodiumalginate.

Respiration was not measured during the present study. Therefore, the substrate uptake and transformation rates or the kinetics could not be calculated precisely; instead, the "economic coefficient" (E) was estimated. According to Perlman (1965), E is defined by the formula:

$$
\mathrm{E}=\frac{\text { mycelium dry weight produced }}{\text { amount of carbon compound consumed }} \times 100
$$

This parameter is widely-used as an orientational measure of substrate utilization efficiency. However, it is assumed that the uronic acids taken up are completely transformed into fungal biomass, and that any respiratory consumption, with eventual release of metabolites from the mycelium, is ignored. In Table 1, the economic coefficients for the two deuteromycetes are calculated. They are: $48.63 \%$ for A. cruciatus and

Table 1. Mycelial dry-weight production and consumption of uronic acids from sodiumalginate degradation by two marine deuteromycetes after 25 days of growth in sodiumalginate broth (NaPYNS) at $25^{\circ} \mathrm{C}$ in the dark

\begin{tabular}{|lcccc|}
\hline \multicolumn{1}{|c}{ Fungal species } & $\begin{array}{c}\text { Strain } \\
\text { KMPB } \\
(\mathrm{No})\end{array}$ & $\begin{array}{c}\text { Mycelial } \\
\text { dry weight } \\
(\mathrm{mg} / \mathrm{ml})\end{array}$ & $\begin{array}{c}\text { Uronic acids } \\
\text { cunsumed } \\
(\mathrm{mg} / \mathrm{ml})\end{array}$ & $\begin{array}{c}\text { Economic } \\
\text { coefficient } \\
(\%)\end{array}$ \\
\hline $\begin{array}{l}\text { Asteromyces cruciatus } \\
\text { Dendryphiella salina }\end{array}$ & $\begin{array}{c}\text { H 54a } \\
\text { H 800/1 }\end{array}$ & $\begin{array}{l}0.89 \\
0.82\end{array}$ & 1.83 & 48.63 \\
KMPB $=$ "Kulturensammlung Mariner Pilze, Bremerhaven" & & 38.86 \\
\hline
\end{tabular}

$38.86 \%$ for $D$. salina. In the calculation, we assumed that nutrients other than sodiumalginate had been completely taken up by the fungi. Thus, the total weight of these nutrients $(1.6 \mathrm{mg} / \mathrm{ml})$ was subtracted from the mycelial dry-weight determinations.

\section{DISCUSSION}

Polyuronides are of widespread occurrence in nature, e.g. in pectins of plant cell walls, as alginates in marine brown algae and bacteria, and in mucopolysaccharides (hyaluronides and chondroitinsulfate) of connective tissue and cartilage in animals and human beings. Despite this, uronic acids have been identified in fungal cells or cell walls only in the zygomycetes (Bartnicki-Garcia, 1970; Flores-Carreón et al,, 1985). Therefore, it might be assumed that in marine deuteromycetes the diverse mono- and di-uronic acids, following absorption, are not incorporated directly into the fungal cell material, but undergo intracellular metabolic changes. We are not aware of any detailed study on the 
uptake and metabolism of uronides or uronic acids by deuteromycetes. But, analogous to bacteria (Preiss \& Ashwell, 1962), it might be assumed that the uronic acid molecules are first reduced to keto-deoxy-gluconate, then phosphorylated, split-up into pyruvate and triose-phosphate, and then enter definite catabolic and anabolic pathways leading finally to the production of cell material (resulting in an increase of biomass) and energy (via respiration).

The "economic coefficient" was estimated according to Perlman (1965). He presented a critical evaluation of the economic coefficient, which in fact is the weakest measure of substrate utilization efficiency. Nevertheless, the economic coefficient can provide a rough estimate of substrate utilization efficiency, and can allow comparison with other fungi. The values for A. cruciatus $(48.6 \%)$ and $D$. salina $(38.9 \%)$ are in close agreement with those reported in the literature for terrestrial fungi, which are, for example, in the range of $15-61 \%$ for Aspergillus niger, $27-41 \%$ for Phycomyces blakesleeanus, and $13.9-40.0 \%$ for Rhizopus nigricans $(=R$. stolonifer), two zygomycetes (Fluri, 1959; Perlman, 1965). Moreover, the magnitude of the E-value can provide insight into the relative participation of the three involved metabolic processes: respiration, metabolite production and release, and biomass production. In the present study, only the latter was studied. If, however, respiration and metabolite release are accepted and considered additionally, this would lead to a reduction of the estimated economic coefficients. Conversely, it is possible to deduce from the economic coefficient whether, and to what extent, respiration and/or metabolite release might be involved in the utilization of the respective substrate. Thus, from the economic coefficients estimated for $A$. cruciatus and $D$. salina with respect to the uptake and metabolism of uronic acids derived from fungal sodiumalginate degradation, it might be concluded that at least some of the absorbed uronic acids may have been used for respiratory processes to provide energy for the various cellular activities. The amount of released metabolites from the growing mycelia was not measured in this study, and remains unknown.

Metabolic processes always affect the natural ecosystem. Our findings show that certain marine fungi must have an important impact on kelp-based ecosystems. These fungi participate in the degradation of both alginates and algal detritus. They are involved in such diverse ecological processes as the following: remineralization of organic substances; nutrient recycling; detritus degradation and enrichment; biomass production; food availability for predators, e.g. mycovorous nematodes (Meyers \& Hopper, 1973); production and recycling of dissolved organic matter via the microbial loop, and finally the carbon cycle in general.

\section{CONCLUSIONS}

In conclusion, our results indicate that not only bacteria, micro- and meiofaunal organisms, such as ciliates, nematodes, harpacticoid copepods, and amphipods, but also marine fungi, decompose alginates originating from living and/or dead brown algal material in the marine ecosystem. However, the number of higher marine fungi actively degrading alginates may be low. Despite this, two strains of $A$. cruciatus and $D$. salina were shown to degrade sodiumalginate by secreting an effective alginase enzyme complex, consisting of alginate lyase as well as hydrolase activities. The fungi could utilize the uronic acid breakdown products efficiently for the production of fungal 
biomass and to some extent for respiration. This is clearly documented by economic coefficients of 48.6 and 38.9 for A. cruciatus and D. salina, respectively.

The results of this study broaden our understanding of the role of marine fungi in macroalgal-degradation communities as well as in the marine ecosystem in general. Marine fungi appear to play a greater role, at least in nearshore kelp-based ecosystems, than was previously realized.

Acknowledgements. Our sincere thanks are due to Dr. L. Medlin for helpful comments and for taking care of the English version of the manuscript. We are also grateful to $\mathrm{M}$. Sündermann for accurate technical assistance. This is publication No. 747 of the Alfred-Wegener-Institute for Polarand Marine Research, Bremerhaven, Germany.

\section{LITERATURE CITED}

Bartnicki-García, S., 1970. Cell wall composition and other biochemical markers in fungal phylogeny. In: Phytochemical phylogeny. Ed. by J. B. Harborne. Acad. Press, New York, 81-103.

Blumenkrantz, N. \& Asboe-Hansen, G., 1973. New method for quantitative determination of uronic acids. - Analyt. Biochem. 54, 484-489.

Bushell, M. E. (Ed.), 1983. Microbial polysaccharides. - Prog. ind. Microbiol., 18, 1-25.

Chan, E. C. S. \& McManus, E. A., 1969. Distribution, characterization, and nutrition of marine microorganisms from the algae Polysiphonia lanosa and Ascophyllum nodosum. - Can. J. Microbiol. 15, 409-420.

Chesters, C. G. C. \& Bull, A. T., 1963. The enzymatic degradation of laminarin. - Biochem. J. 86, 28-31.

Chesters, C. G. C., Turner, M. \& Apinis, A., 1956. Studies of the decomposition of seaweeds and seaweed products by microorganisms. - Proc. Linn. Soc. Lond. 166, 87-97.

Flores-Carreón, A., Balcazar, R. \& Ruíz-Herrera, J., 1985. Characterization of glucuronosyl transferase from Mucor rouxii: requirement for polyuronide acceptors. - Exp. Mycol. 9, 294-301.

Fluri, R., 1959. Der Kohlenhydrathaushalt eines Schimmelpilzes (Phycomyces blakesleeanus) in Abhängigkeit von den Kulturbedingungen. - Arch. Mikrobiol. 33, 195-222.

Gunkel, W., Crow, S. \& Klings, K.-W., 1983. Yeast population increases during degradation of Desmarestia viridis (Phaeophyceae) in seawater model microecosystems. - Mar. Biol. 75, 327-332.

Haythorn, J. M., Jones, E. B. G. \& Harrison, J. L., 1980. Observations on marine algicolous fungi including the hyphomycete Sigmoidea marina sp. nov. - Trans. Br. mycol. Soc 74, 615-624.

Kohlmeyer, J. J. \& Kohlmeyer, E., 1979. Marine mycology - the higher fungi. - Acad. Press, New York, $690 \mathrm{pp}$.

Lyman, J. \& Fleming, R. H., 1940. Composition of seawater. - J. mar. Res. 3, 134-146.

Lüning, K., 1985. Meeresbotanik. Thieme, Stuttgart, 375 pp.

Meyers, S. P. \& Hopper, B. E., 1973. Nematological-microbiological interrelationships and estuarine biodegradative processes. In: Estuarine microbial ecology. Ed. by L. H. Stevenson \& R. R. Colwell. Univ. South Carolina Press, Columbia, 483-488.

Miller, J. D. \& Whitney, N. J., 1981. Fungi from the Bay of Fundy. II. Observations on fungi from living and cast seaweed. - Botanica mar. 24, 405-411.

Perlman, D., 1965. The chemical environment for fungal growth. In: The fungi. Ed. by G. C. Ainsworth \& A. S. Sussmann. Acad. Press, New York 1, 479-489.

Preiss, J. \& Ashwell, G., 1962. Alginic acid metabolism in bacteria. I. Enzymatic formation of unsaturated oligosaccharides and 4-deoxy-L-erythro-5-hexoseulose uronic acid. - J. biol. Chem. 237, 309-316.

Rieper-Kirchner, M. 1989. Microbial degradation of North Sea macroalgae: field and laboratory studies. - Botanica mar. 32, 241-252.

Schatz, S., 1980. Degradation of Laminaria saccharina by higher fungi: a preliminary report. Botanica mar. 23, 617-622. 
Schatz, S., 1984. Degradation of Laminaria saccharina by saprobic fungi. - Mycologia 76, 426-432.

Schaumann, K. \& Weide, G., 1990. Enzymatic degradation of alginate by marine fungi. - Hydrobiologia 204/205, 589-596.

Schlegel, H. G., 1985. Allgemeine Mikrobiologie. Thieme, Stuttgart, $344 \mathrm{pp}$.

Wainwright, M., 1980. Alginate degradation by the marine fungus Dendryphiella salina. - Mar. Biol. Lett. 1, 351-354.

Wainwright, M. \& Sherbrock-Cox, V., 1981. Factors influencing alginate degradation by the marine fungi: Dendryphiella salina and D. arenaria. - Botanica mar. 24, 489-491.

Waksman, S. A., Carey, C. L. \& Allen, M. C., 1934. Bacteria decomposing alginic acid. - J. Bact. 28, 213-220. 